\title{
Examining the Pearls of Islamic Education Through the History of the Prophet Adam Alaihi Salam in the Quran
}

\section{Menelaah Mutiara Pendidikan Islam Menerusi Sejarah Nabi Adam Alaihi Salam dalam al-Quran}

\author{
Mikdar Rusdi ${ }^{*}$, Md Azmi Omar ${ }^{1}$, Norasimah Omar ${ }^{1}$, Tiara Basman ${ }^{1}$, Suhaila \\ Abdul Majid ${ }^{2}$ \\ ${ }^{1}$ Fakulti Usuluddin, \\ Kolej Universiti Perguruan Ugama Seri Begawan, BRUNEI \\ ${ }^{2}$ Faculty of Humanities, Arts and Heritage, \\ Universiti Malaysia Sabah, MALAYSIA \\ *Corresponding Author
}

DOI: https://doi.org/10.30880/jstard.2020.02.03.004

Received 30 September 2020; Accepted 30 November 2020; Available online 31 January 2020

\begin{abstract}
The history of the Prophet Adam Alaihi salam became the starting point of human civilization, as the caliph and the first man of course the history and pearl of education became the focus for researchers to see further the appropriateness of the value of the caliph's education to be applied at this time. Looking at the value of the caliph's education as a prospered of the earth will lead to the creation of universal human well-being because it will return to the principles of education per the nature of human creation. The history of the prophet Adam alaihi salam is a solution that can be a reference to the model of Islamic education because basically the prophet and apostle are the first teachers (educators) sent to this earth to guide his people not to deviate from the concept of its creator. On the other hand, the history of the Prophet Adam Alaihi Salam is among the 25 prophets and messengers mentioned in the Quran and the implications of the pillars of faith that must be believed and believed to be true, in this case studying the story are part of the guidance of the pillars of faith that certainly affect the journey believers, This paper can to some extent provide a new formula in exploring the Islamic education system through the study of the history of the Prophet Adam Alaihi Salam starting from its creator, the interaction between angels and God as well as the influence and involvement of the devil in heaven as a process of maturity.
\end{abstract}

Keywords: al-Quran, Prophet Adam Alaihi Salam, education, caliph 


\begin{abstract}
Abstrak: Sejarah Nabi Adam Alaihi salam menjadi titik permulaan peradaban manusia, sebagai khalifah dan manusia pertama sudah tentu sejarah dan mutiara pendidikannya menjadi tumpuan bagi para pengkaji untuk melihat lebih jauh kesesuaian nilai pendidikan khalifah untuk diterapkan pada masa ini. Meneropong nilai pendidikan khalifah sebagai pemakmur bumi akan bermuara kepada terciptanya kesejahteraan manusia sejagat kerana akan kembali kepada prinsip pendidikan yang sesuai dengan fitrah kejadian manusia. Sejarah nabi Adam alaihi salam adalah solusi yang boleh jadi rujukan model pendidikan islami kerana pada dasarnya nabi dan rasul adalah guru (pendidik) pertama yang diutus kemuka bumi ini untuk memberi petunjuk kepada umatnya agar tidak keluar dari konsep penciptaanya. Di sisi lain, sejarah Nabi Adam Alaihi Salam adalah antara 25 nabi dan rasul yang disebut dalam al Quran dan implikasi dari rukun iman yang wajib diimani dan diyakini kebenarannya, dalam hal ini mengkaji kisahnya adalah bahgaian dari tuntunan rukun iman yang tentunya memberi kesan kepada perjalanan hidup orang yang beriman, Kertas kerja ini sedikit sebanyak dapat memberi formula baru dalam meneroka sistema pendidikan islam menerusi pengkajian sejarah Nabi Adam Alaihi Salam bermula dari penciptaanya, interaksi antara malaikat dengan Allah serta pengaruh dan keterlibatan iblis dalam syurga sebagai proses kematangan khalifah sebelum turun ke bumi.
\end{abstract}

Kata Kunci: al-Quran, nabi nabi adam alaihi salam, pendidikan, khalifah

\title{
1. Pengenalan
}

Sejarah Nabi Adam a.s. dalam al Quran bagaikan mutiara yang sentiasa berkilau dimata pengkaji al Quran kerana setiap kali merenungkan ayat-ayatnya akan memancarkan kilauan yang dapat menerangi jalan kehidupan. Sudah tentu perjalanan kehidupan umat manusia tidak akan luput dari keperluan mereka dari petunjuk yang dapat menerangi langkah-langkah kehidupan terutama dari segi pencerahan dalam mencari bentuk pendidikan yang terbaik untuk anak cucunya.

Episode sejarah penciptaan Nabi Adam a.s. dalam al Quran bila dicermati akan kita jumpai beberapa nilai pendidikan yang sangat relevan untuk diamalkan dalam mendidik generasi yang cintakan peradaban. Nilai pendidikan yang dimaksudkan ini dapat dilihat dari proses penciptaan Nabi Adam a.s. dengan adanya dialog antara Allah Subhanah Wata ala dengan malaikatnya, kemudian diteruskan dengan pencarian bukti atas keraguan sangkaan malaikat terhadap fakta dan terakhir perlunya mendepankan nilai adab dalam menghadapi apa-apa keputusan pengkajian ilmu.

\section{Nabi Adam Alaihi Salam dan Konsep Dialog}

Dialog adalah satu elemen penting bagi menemukan kesepakatan dalam sesuatu perkara yang dipermasalahkan, dialog sangat menentukan kedua belah pihak yang bersengketa untuk saling memahami permasalahan yang sebenarnya sehingga ada rasa saling menerima terhadap keputusan yang sudah dipersetujui agar suatu hari nanti tidak berlaku sikap saling menyalahkan kebijakan yang sudah diputuskan bersama.

Sejarah penciptaan Nabi Adam a.s. di mulakan dengan dialog antara Allah Subhanah Wata ala dengan malaikatnya dengan pemakluman dari Allah Subhanah Wata`ala kepada malaikat akan penciptaan seorang khalifah bernama Nabi Adam a.s., malaikat dalam hal ini merespon rencana itu dengan mengemukakan hujjah yang menyatakan bahawa khalifah akan melakukan kerosakan di bumi dan melakukan penumpahan darah sedangkan malaikat sendiri sentiasa bertasbih dan memuji Tuhannya.

Antara tujuan dialog ini agar suatu hari nanti malaikat tidak terkejut ketika mengembang amanah dari Allah Subhanah Wata`ala berkaitan manusia baik berupa wahyu yang diturunkan kepada nabi dan rasul mahupun berkaitan dengan amalan individu yang perlu dicatat atau rezeki yang perlu diaturkan kepada setiap umat manusia.

Dialog antara Allah Subhanah Wata ala dengan malaikatNya dikisahkan dalam surah al-Baqarah ayat 30, di mana Allah Subhanah Wata ala berfirman:

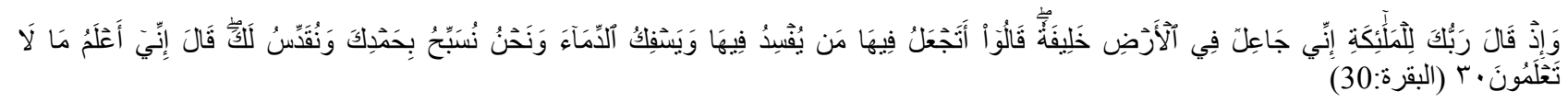

Maksudnya:

Dan (ingatlah) ketika Tuhanmu berfirman kepada Malaikat; "Sesungguhnya Aku hendak menjadikan seorang khalifah di bumi". Mereka bertanya (tentang hikmat ketetapan Tuhan itu dengan berkata): "Adakah Engkau (Ya Tuhan kami) hendak menjadikan di bumi itu orang yang akan membuat bencana dan menumpahkan darah (berbunuh-bunuhan), padahal kami sentiasa bertasbih dengan memujiMu dan mensucikanMu?". Tuhan berfirman: "Sesungguhnya Aku mengetahui akan apa yang kamu tidak mengetahuinya"

Nilai pendidikan yang ditanamkan oleh Allah Subhanah Wata`alamelalui dialog di atas adalah untuk menekankan perlunya konsep ini bagi mendapatkan natijah yang sempurna. Bukan bermakna Allah Subhanah Wata ala perlukan 
dialog ini bagi penciptaan manusia kerana Allah Subhanah Wata`ala yang Maha kaya dari makhluknya dan bukan juga kerana Allah Subhanah Wata ala tidak tahu atas kemungkinan akan berlaku seperti yang dicadangkan oleh malaikat kerana Allah Subhanah Wata`ala Maha Tahu atas segala sesuatu.

Namun tujuan yang sebenarnya adalah pengajaran Allah Subhanah Wata`ala kepada umat manusia akan pentingnya dialog dan perlunya mendepankan nilai-nilai dialog kepada diri kita sebelum hendak melakukan perancangan. Allah Subhanah Wata`ala tidak meletak bentuk dialog sebelum pencipataan Nabi Adam a.s. tanpa hikmah atau sebab melainkan ada tujuan pengajaran disebaliknya agar umat manusia memandang serius manfaat dialog dalam kehidupan kita.

Dialog pada umumnya terbahagi kepada dua bahagian, iaitu dialog yang berlaku antara seseorang dengan dirinya sendiri atau yang disebut dengan dialog dalaman atau الحوار الداخلي dialog dialog luaran atau الحوار الخارجي dang berlaku dengan orang lain.

Dialog dalaman sering berlaku dalam bentuk interpersonal iaitu jika sesorang memerlukan pemerhatian lebih terhadap sesuatu isu sehingga berlakulah tanya-jawab dalam diri seseorang, contoh firman Allah Subhanah Wata ala :

Maksudnya:

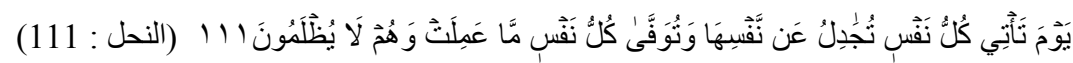

«(Allah akan mengampunkan dosa-dosa mereka itu pada hari kiamat), hari tiap-tiap diri datang membela dirinya semata-mata, dan tiap-tiap diri disempurnakan balasan apa yang ia telah kerjakan (sama ada baik atau jahat), sedang mereka tidak akan dianiaya sedikit pun(111)»

Pada firman Allah Subhanah Wata`ala yang lain:

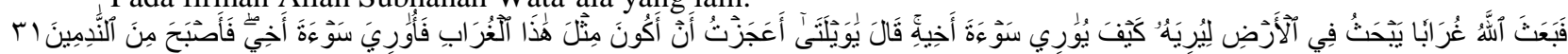

Maksudnya:

«Kemudian Allah hantarkan seekor burung gagak (menyuruhnya) mengorek-ngorek di bumi supaya, diperlihatkan kepada (Qabil) bagaimana cara menimbus mayat saudaranya. (Qabil) berkata: "Wahai celakanya aku! Alangkah lemah serta bodohnya aku, aku tidak tahu berbuat seperti burung gagak ini, supaya aku dapat menimbuskan mayat saudaraku?". Kerana itu menjadilah ia dari golongan orang-orang yang menyesal.

Manakala contoh dialog luaran atau الحوار الخارجي seperti yang berlaku antara Allah Subhanah Wata`ala dengan malaikatnya dan banyak lagi contoh dalam al-Quran khasnya yang berlaku dalam kisah nabi dan rasul dengan umatnya.

Malaikat Jibril juga mengamalkan konsep ini dalam penyampaian ilmu ketika datang berjumpa dengan Nabi Muhammad Sallallahu Alaihi Wasallam untuk mengajarkan tentang urusan agama dengan bertanya apa itu Islam, Iman dan Ihsan seperti yang disebut dalam hadis:

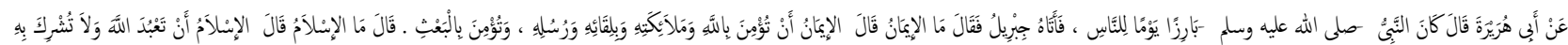

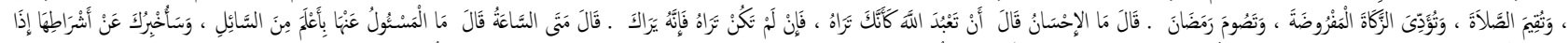

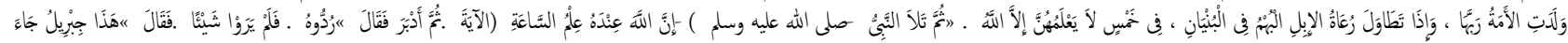

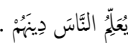

Maksudnya:

Ketika nabi Muhammad Sallallahu Alaihi Wasallam hedak mengajarkan sesuatu kepada Abdullah bin Abas juga menggunakan uslub dialog seperti yang disebut dalam hadis:

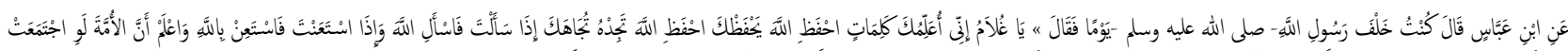

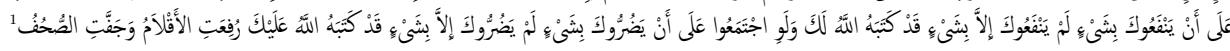

Maksudnya:

Daripada Ibn al-'Abbas Radhiallah Anhu berkata: Aku pernah duduk di belakang Nabi Sallallahu Alaihi Wasallam pada suatu hari, lalu Baginda bersabda kepadaku: Wahai anak! Sesungguhnya aku mahu ajarkan engkau beberapa kalimah: Peliharalah Allah nescaya Allah akan memeliharamu. Peliharalah Allah nescaya engkau akan dapati Dia di hadapanmu. Apabila engkau meminta, maka pintalah dari Allah. Apabila engkau meminta pertolongan, maka mintalah pertolongan dengan Allah. Ketahuilah bahawa kalau umat ini berkumpul untuk memberikan sesuatu manfaat kepadamu, mereka tidak akan mampu memberikanmu manfaat kecuali dengan suatu perkara yang memang Allah telah tentukan untukmu. Sekiranya mereka berkumpul untuk memudharatkan kamu dengan suatu mudharat, nescaya mereka tidak mampu

\footnotetext{
${ }^{1}$ Al-Tirmizy, Muhammad bin Isa Abu Isa al Tirmizy, al-Jami` al-Sahih Sunan al Tirmizy, Dar Ihya al-Turath al-Araby, Beirut, Juz 4 halaman 667
} 
memudharatkan kamu kecuali dengan suatu perkara yang memang Allah telah tentukannya untukmu. Pena-pena telah diangkatkan dan lembaran-lembaran telah kering (dakwatnya).

\section{Nabi Adam Alaihi Salam dan Konsep Pencarian Fakta dan Bukti}

Suatu konsep atau teori tidak akan dikira sempurna tanpa dibuktikan dengan fakta, dengan demikian, penciptaan Nabi Adam a.s. menerusi dialog antara Allah Subhanah Wata`ala dan malaikatnya dibuktikan dengan pembenaran fakta yang Allah Subhanah Wata`ala buat dalam bentuk pengajaran ilmu kepada Nabi Adam a.s. lalu dibuktikan dengan soalan yang ditujukan kepada malaikat sehingga mendatangkan natijah bahawa Allah Subhanah Wata`ala Maha Mengetahui atas segala urusan yang berkaitan dengan makhlukNya. Firman Allah Subhanah Wata`ala :

Maksudnya:

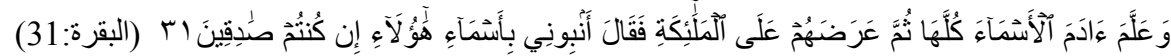

Dan Ia telah mengajarkan Nabi Adam, akan segala nama benda-benda dan gunanya, kemudian ditunjukkannya kepada malaikat lalu Ia berfirman: "Terangkanlah kepadaKu nama benda-benda ini semuanya jika kamu golongan yang benar.

Sungguh pembuktian yang ditunjukkan oleh Allah Subhanah Wata ala dengan membandingkan ilmu yang sudah diajarkan kepada Nabi Adam a.s. dengan ilmu yang dimiliki oleh malaikat tidak seimbang sehingga malaikat menyedari akan kurangnya ilmu mereka dan kelebihan ilmu yang dimiliki oleh Nabi Adam a.s. yang berujung pangkal kepada pengakuan malaikat akan kekurangan pengetahuannya tentang urusan ghaib yang akan berlaku kepada Nabi Adam a.s. dan anak cucunya di masa akan datang.

Penulis sendiri melihat pembuktian yang ditunjukkan dalam ayat di atas bukan semata-mata untuk melihat keMaha Mengetahuinya Allah Subhanah Wata ala berbanding malaikatNya, kerana sememangnya tidak akan sebanding antara Tuhan yang Maha Pencipta dengan makhluknya yang serba kekurangan, akan tetapi Allah Subhanah Wata ala mahukan kita untuk mengambil iktibar dari episod ini kerana tiada sesuatu yang sia-sia di sisi Allah Subhanah Wata`ala dan tentunya ada hikmah disebalik itu yang bertujuan untuk hambanya agar tidak mudah mengambil sikap memandaimandai dalam berpendapat atau mengambil keputusan tanpa bukti yang kukuh akan tetapi perlu didasari dengan ilmu yang mendalam dan fakta.

Dalam mencari pakta atau pembuktian suatu teori memang perlu kepada pengetahuan yang mendalam agar teori yang diyakini kebenarannya tidak mendatangkan hasil yang pincang terutama ketika sudah mengarah kepada pengaplikasian teori yang mungkin akan berakibat fatal sekiranya berpihak kepada golongan tertentu sahaja, atau berat sebelah sehingga natijah yang dihasilkan tidak boleh diaplikasikan untuk semua peringkat.

Konsep pencarian fakta dalam mencari kebenaran juga telah dilakukan oleh Nabi Ibrahim a.s. ketika berdialog dengan kaumnya dalam mencari Tuhan, seperti firman Allah Subhanah Wata`ala :

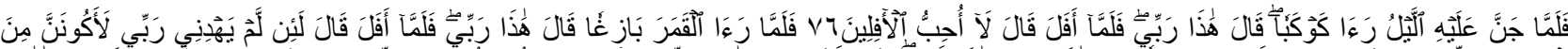

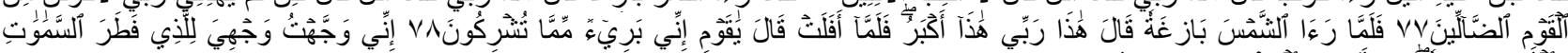

Maksudnya:

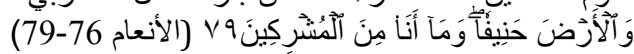

Maka ketika ia berada pada waktu malam yang gelap, ia melihat sebuah bintang (bersinar-sinar), lalu ia berkata: "Inikah Tuhanku?" Kemudian apabila bintang itu terbenam, ia berkata pula: "Aku tidak suka kepada yang terbenam hilang"(76) Kemudian apabila dilihatnya bulan terbit (menyinarkan cahayanya), dia berkata: "Inikah Tuhanku?" Maka setelah bulan itu terbenam, berkatalah dia: "Demi sesungguhnya, jika aku tidak diberikan petunjuk oleh Tuhanku, nescaya menjadilah aku dari kaum yang sesat"(77) Kemudian apabila dia melihat matahari sedang terbit (menyinarkan cahayanya), berkatalah dia: "Inikah Tuhanku? Ini lebih besar". Setelah matahari terbenam, dia berkata pula: ' Wahai kaumku, sesungguhnya aku berlepas diri (bersih) dari apa yang kamu sekutukan (Allah dengannya)(78) "Sesungguhnya aku hadapkan muka dan diriku kepada Allah yang menciptakan langit dan bumi, sedang aku tetap di atas dasar tauhid dan bukanlah aku dari orang-orang yang menyekutukan Allah (dengan sesuatu yang lain)"(79)

\section{Nabi Adam Alaihi Salam dan Konsep Adab dalam Menuntut Ilmu}

Dalam penciptaan Nabi Adam a.s., Allah Subhanah Wata ala mengajarkan kepada kita satu pengajaran akhlak yang berbentuk adab kepada Tuhan, adab ini didapati dalam dialog antara Allah Subhanah Wata`ala dan malaikatnya sebagai renungan kepada kita semua agar dijadikan contoh dalam menuntut ilmu, oleh kerana adab ini penting sehingga Allah Subhanah Wata`ala memasukan dalam timeline penciptaan Nabi Adam a.s. sebagai khalifah di bumi.

Adab yang diajarkan oleh Allah Subhanah Wata`ala kepada kita adalah adab yang ditunjukkan oleh malaikat ketika merasakan dirinya memiliki ilmu yang terbatas sehingga merespon Allah Subhanah Wata`ala dengan lafaz سبطانك لاعل لنا linale berkara ini disebutkan dalam al-Quran:

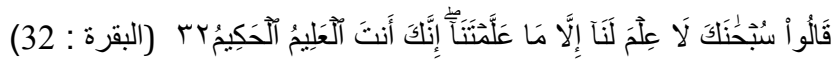


Maksudnya:

Malaikat itu menjawab: "Maha suci Engkau (Ya Allah)! Kami tidak mempunyai pengetahuan selain dari apa yang Engkau ajarkan kepada kami; sesungguhnya Engkau jualah yang Maha Mengetahui, lagi Maha Bijaksana.

Adab yang ditunjukkan oleh malaikat pada ayat di atas memberi ilham baru kepada umat ini agar mendepankan nilai adab dalam menuntut ilmu, sama ada ilmu itu sudah dimiliki atau belum, kerana kepemilikan ilmu adalah hak mutlak bagi Allah Subhanah Wata ala. Kita sebagai umat manusia tidak perlu sombong ketika diberi anugerah ilmu dalam bentuk sedikit atau banyak, kerana sebanyak mana ilmu yang kita miliki tetap dianggap sedikit di sisi Allah Subhanah Wata`ala :

Maksudnya:

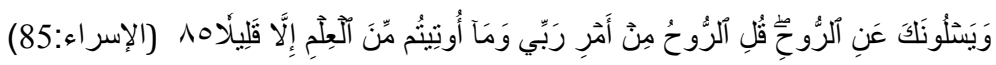

Dan mereka bertanya kepadamu tentang roh. Katakan: "Roh itu dari perkara urusan Tuhanku; dan kamu tidak diberikan ilmu pengetahuan melainkan sedikit sahaja.

Ugama Islam terdiri dari tiga bahagian utama iaitu: Akidah, Syariah dan Akhlak. Adab bahagian yang tidak dapat dipisahkan dari akhlak manakala akhlak adalah perkara utama dalam ugama Islam, Islam menyebut ihsan yang merupakan asas kepada akhlak sebagai dan juga merupakan perkara asas dalam ugama, seperti yang disebut dalam hadith Rasulullah Sallallahu Alaihi Wasallam:

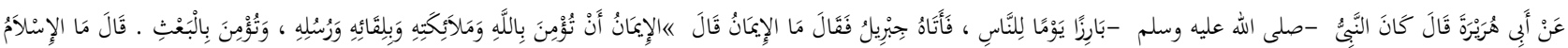

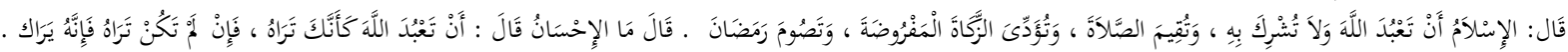

Maksudnya:

Diriwayatkan dari Abu Hurairah berkata; pernah Nabi Nabi Sallallahu Alaihi Wasallam pada suatu hari muncul dekati para sahabat, lalu datang malaikat Jibril bertemunya kemudian bertanya: "Apakah iman itu?” Nabi Sallallahu Alaihi Wasallam menjawab: "Iman itu ialah kamu beriman kepada Allah, malaikat-malaikat-Nya, kitab-kitab-Nya, pertemuan dengan-Nya, Rasul-Rasul-Nya, dan kamu beriman kepada hari kebangkitan”. Kemudian dia berkata: "Apakah Islam itu?" Jawab Nabi Nabi Sallallahu Alaihi Wasallam: "Islam itu ialah kamu mengabdikan diri terhadap Allah dan tidak menyekutukannya dengan suatu apapun, kamu dirikan solat, kamu tunaikan zakat yang diwajibkan, dan berpuasa di bulan Ramadan”. Kemudian dia bertanya lagi: "Apakah ihsan itu?" Nabi Nabi Sallallahu Alaihi Wasallam menjawab: "Kamu menyembah Allah seolah-olah melihat-Nya namun sekiranya kamu tidak dapat melihatNya maka sesungguhnya Dia sentiasa melihatmu.

Kedatangan malaikat jibril untuk berjumpa dengan Nabi Muhammad Sallallahu Alaihi Wasallam lalu menanyakan tiga perkara (Iman, Islam dan Ihsan) dengan menanyakan tentang Ihsan sederet dengan Iman dan Islam menunjukkan perkara tiga perkara asas dalam ugama, dan perkara adab adalah termasuk dalam skop bahasan ihsan bahkan boleh dikatakan termasuk ke dalam 1/3 dari urusan ugama.

\section{Kesimpulan}

Sejarah Nabi Adam Alaihissalam dalam al-Quran diceritakan dalam beberapa episode dan disebutkan dalam beberapa surah al-Quran bahkan lafaz Adam sahaja disebut sebanyak 26 ayat dalam pelbagai surah yang berasingan. Episode perjalanan Nabi Adam Alaihissalam dalam al-Quran tentunya menjadi renungan bagi setiap umat Islam kerana di samping sebagai manusia pertama juga menyandang sebagai khalifah pertama di muka bumi ini, mutiara yang ditorehkan oleh sejarahnya dalam al Quran menjadi nilai yang sangat menarik untuk dijadikan panduan dalam mendidik generasi islamik dalam pelbagai dimensi dan peringkat jenis pendidikan.

\section{Penghargaan}

Penulis ingin mengucapkan terima kasih kepada Fakulti Usuluddin, Kolej Universiti Perguruan Ugama Seri Begawan, Brunei atas bantuan dan maklumat yang diberikan untuk memastikan kejayaan kajian ini.

\section{Rujukan}

[1] Al-Qur`an al-Karim

[2] Al-Biqaci. Burhan al-Din Abu al-Hasan Ibrahim bin ${ }^{c}$ Umar bin Hasan al-Ribat bin ${ }^{c}$ Ali bin Abi Bakr. 1995. Nazm al-Durar fi tanasub al-Ayat wa al-Suwar. Cet.I. Juzuk 5. Beirut. Dar al-Kutub al-'Ilmiyah

[3] Al-Bukhary. Muhammad bin Ismacil bin Ibrahim bin al-Mughirah 1996. Sahih al-Bukhary fi Fath al-Bary. Juzuk 3. Qaherah. Dar Abu Hayyan. 
[4] Al-Mawardy, Abu al-Hasan ${ }^{\mathrm{c}}$ Ali bin Muhammad bin Habib al-Basry al-Bughdady .t.th. al-Nukat wa al- ${ }^{c}$ Uyun. Juzuk I. Beirut. Dar al-Kutub al-'Ilmiyah

[5] Al-Qurtuby. Abu ${ }^{\mathrm{c}}$ Abdullah Muhammad Bin Ahmad. 1967. Al-Jamic Li Ahkam Al-Qur`an . Qaherah. Dar al-Katib al- ${ }^{\mathrm{C}}$ Araby Li al-Tabac ah Wa al-Nashr.

[6] Al-Suyuty. Jalal al-Din ${ }^{\mathrm{c}}$ Abd al-Rahman bin Abu Bakr. 2000. al-Dur al-Manthur fi al-Tafsir al-Ma'thur. Beirut. Cet 1. Jilid 1. Dar al-Kutub al-'Ilmiyyah.

[7] Al-Tabary. Abu Jacfar Muhammad bin Jarir. 2005. Jamic al-Bayan ${ }^{c}$ an ta`wil ay al-Qur`an. Ishraf Wa Taqdim ${ }^{\mathrm{c}}$ Abd al-Hamid ${ }^{\mathrm{c}}$ Abd al-Muncim Madkur. Qaherah. Dar al-Salam.

[8] Fakhr al-Razy. Abu ${ }^{\mathrm{c}} \mathrm{Abd}$ Allah Muhammad bin ${ }^{\mathrm{c}}$ Umar bin al-Hasan bin al-Husain al-Taymy al-Bakry al-Razy. 2002. Mafatih al-Gayb. Beirut Dar al-Fikr.

[9] Ibn ' Ashur, Muhammad al-Tahir.1984. al-Tahrir wa al-Tanwir. Juzuk 18. Tunis. Dar al-Tunisiyah li al-Nashr wa al-Tawzic

[10] Ibn Kathir. 'Imad al-Din Abu al-Fida` Ismacil bin Kathir al-Qurashy al-Dimashqy. 1393H. Tafsir Al-Qur'an Al${ }^{c}$ Azim. Tahqiq Muhammad ${ }^{c}$ Ali Al-Sabuny. Cet.1. Beirut. Dar Al-Qur`an Al-Karim

[11] Shihab M.Quraish. 2004. Dia Dimana-Mana Tangan Tuhan Disebalik Setiap Fenomena. Cet. 1. Jakarta. Lentera Hati.

[12] Tantawy, Muhammad al-Sayyid. 1984. al-Tafsir al-Wasith li al-Qur`an al-Karim. Juzuk 9. al-Qahirah. Dar alMacarif 